\title{
Diet scores and cardio-metabolic risk factors among Guatemalan young adults
}

\author{
Cria O. Gregory ${ }^{1}$, Marjorie L. McCullough ${ }^{1,2}$, Manuel Ramirez-Zea ${ }^{3}$ and Aryeh D. Stein ${ }^{1,4 *}$ \\ ${ }^{1}$ Nutrition and Health Sciences Program, Graduate Division of Biological and Biomedical Sciences, Emory University, \\ 1462 Clifton Road, NE, Atlanta, GA 30322, USA \\ ${ }^{2}$ Epidemiology and Surveillance Research, American Cancer Society, 250 Williams Street, Atlanta, GA 30303, USA \\ ${ }^{3}$ Institute of Nutrition of Central America and Panama (INCAP), PO Box 1188, Calzada Roosevelt, Zona 11, Guatemala City, \\ Guatemala 01011 \\ ${ }^{4}$ Hubert Department of Global Health, Rollins School of Public Health, Emory University, 1518 Clifton Road, NE, \\ Atlanta, GA 30322, USA
}

(Received 1 May 2008 - Revised 21 September 2008 - Accepted 25 September 2008 - First published online 24 November 2008)

We assessed the association of four diet quality scores with multiple cardio-metabolic outcomes among Guatemalan young adults experiencing the nutrition transition. We obtained cross-sectional dietary, demographic, anthropometric and cardio-metabolic risk factor data from 1220 Guatemalan adults (mean age 32.7 (SD 5.8) years) in 2002-4, and computed a Recommended Food Score (RFS), Not Recommended Food Score (NRFS), Food Variety Score (FVS) and the Dietary Quality Index-International (DQI-I). All four scores were correlated with energy intake ( $r$ 0.23-0.49; all $P<0 \cdot 01$ ), but had varying associations with socio-demographic characteristics, lifestyle factors and nutrient intakes. None of the scores was inversely associated with the metabolic syndrome or its components; rather some were positively associated with risk factors. Among both men and women the DQI-I was positively associated with BMI $\left(\mathrm{kg} / \mathrm{m}^{2} ; \beta=0 \cdot 10,95 \%\right.$ CI $0.003,0.21$ (men); $\beta=0.07,95 \%$ CI $0.01,0 \cdot 14$ (women) and waist circumference $(\mathrm{cm} ; \beta=0.02,95 \%$ CI $0.01,0.03(\mathrm{men}) ; \beta=0.02,95 \% \mathrm{CI}=0.01,0.02$ (women)). Among men, the RFS was positively associated with TAG $(\mathrm{mg} / \mathrm{l} ; \beta=0.11,95 \%$ CI $0 \cdot 02,0 \cdot 21)$ and glucose $(\mathrm{mg} / \mathrm{l} ; \beta=0.13: 95 \%$ CI $0.03,0 \cdot 22)$. We conclude that indices of diet quality are not consistently associated with chronic disease risk factor prevalence in this population of Guatemalan young adults.

Nutrition transition: Diet scores: Cardio-metabolic risk: Developing countries: Guatemala

Many developing countries are experiencing substantial increases in the prevalence of overweight and obesity and in the incidence of CVD and diabetes ${ }^{(1-3)}$. An important predisposing factor is the nutrition transition, a shift in dietary patterns towards increased overall energy intake and consumption of partially hydrogenated and saturated fats, simple carbohydrates and animal source foods, and decreased consumption of fibre ${ }^{(4)}$. The apparent abundance of food can mask persistent micronutrient deficiencies ${ }^{(5)}$. This is particularly worrisome given that deficiencies in several B vitamins, zinc and antioxidants may exacerbate the increased risk of CVD and diabetes posed by excess body weight ${ }^{(6,7)}$.

Dietary diversity is often recommended as a strategy to ensure diet quality ${ }^{(8)}$. Common measures of diet quality include scores that are derived from individual foods or food groups, as well as more complex scores that also incorporate information on intakes of nutrients. The Dietary Quality Index-International (DQI-I), developed to allow for crossnational comparisons of diet quality, exemplifies the latter ${ }^{(9)}$. However, in many settings a combination of low education and literacy, the sharing of foods from a common bowl, and insufficient data on the nutrient composition of local foods can make it difficult to obtain individual-level data precise enough to calculate some of the more complex scores ${ }^{(10)}$. Simple diversity and variety scores have been positively associated with intake of micronutrients, fruits, vegetables and grains in developing countries ${ }^{(11-13)}$. However, these scores may also be positively associated with saturated fats, refined foods and sugars ${ }^{(14)}$, and thus not capture desirable patterns for cardio-metabolic disease prevention.

Guatemala is in the midst of the nutrition transition, with substantial undernutrition evidenced by a high prevalence of stunting and anaemia ${ }^{(15-17)}$, and substantial recent increases in overweight, obesity and chronic diseases ${ }^{(18,19)}$. We aimed to characterize the diet of a sample of Guatemalan young adults, and assess how various dietary scores (Food Variety Score (FVS), Recommended Food Score (RFS), Not Recommended Food Scores (NRFS) and the DQI-I) were associated with cardio-metabolic risk.

\section{Methods}

We used data collected during the 2002-4 cross-sectional follow-up of the Institute of Nutrition of Central America

Abbreviations: DQI-I, Dietary Quality Index-International; FVS, Food Variety Score; INCAP, Institute of Nutrition of Central America and Panama; NRFS, Not Recommended Food Score; RFS, Recommended Food Score.

* Corresponding author: Dr Aryeh D. Stein, fax +1 404727 1278, email Aryeh.Stein@emory.edu 
and Panama (INCAP) Nutrition Cohort Study ${ }^{(20,21)}$. Children born from 1962 to 1977 ( $n$ 2392) participated in the original trial; we attempted to study the 1855 individuals (age 25-42 years, and their spouses, if married) who were not known to have died or to have left Guatemala. Full data on tracing and follow-up are provided elsewhere ${ }^{(22)}$. All data collection was approved by review boards at both INCAP and Emory University and written informed consent was obtained from all participants.

\section{Dietary assessment}

We used an interviewer-administered fifty-two-item FFQ to ascertain typical consumption over the previous 3 months. The FFQ included traditional staples of the Guatemalan diet, some 'Western' or transitional foods, and an open-ended section to allow for the inclusion of seasonal or less widely consumed fruits and vegetables. The range of write-in fruits and vegetables was from zero to nine (mean 4.4 (SD 2.0)). The fruits and vegetables most commonly listed (reported by $25-66 \%$ of participants) in the open-ended section were: squash, mango, apple, watermelon, orange, banana, cucumber and cabbage. We estimated nutrient intakes using the INCAP nutrient database, which is based on foods commonly consumed in Guatemala and supplemented with data from the US Department of Agriculture Nutrient Database. As compared to three non-consecutive $24 \mathrm{~h}$ recalls, the FFQ overestimates energy intake by approximately $1506 \mathrm{~kJ}(360 \mathrm{kcal})$, gives good measures of macronutrient intake and gives reasonably reliable measures of micronutrient intake ${ }^{(23)}$.

\section{Calculation of dietary scores}

We calculated RFS and NRFS ${ }^{(24,25)}$, intended to be used simultaneously in statistical models. Within each scale, one point was awarded for each food that was consumed at least weekly. The RFS included beans, tortillas, cereals, chicken, fish, carrots, guicoy (a type of squash), and one point for each type of fruit and vegetable mentioned, giving a total possible RFS of 16. The NRFS included cream/butter, french fries/fried plantains, chicharrones (fried pork skin), chorizo/salchicha (different types of sausages), red meat, tacos, tamales, hamburgers, hot dogs, pizza, chips, cake, sweet bread, ice cream and candy, for a total possible NRFS of 15. Foods that we could not confidently describe as recommended or not recommended were not included in either score; for example the milk item did not distinguish between lower and higher fat content and the bread and rice items did not distinguish between whole and refined grains. Due to substantial cultural variation in the typical diet, our scores differ from previously used RFS and NRFS. Similar to these original scores, foods high in fibre, lean protein and micronutrients were included in the recommended category, while foods high in saturated fat and sugar were included in the non-recommended category.

We calculated a FVS by awarding one point for any unique food that was reported as being consumed at least weekly ${ }^{(26)}$. We did not include alcoholic or sweetened beverages or condiments such as jam, honey, mayonnaise or butter in our score. This resulted in thirty individual line items, to which we added one point for each fruit and vegetable that was mentioned in the open-ended section.

Both foods and nutrients are used to calculate the DQI-I ${ }^{(9)}$. A total possible score of 100 is comprised of sub-scores for variety of food groups and protein sources (twenty points), adequacy of fruits, vegetables, grains, fibre, protein, iron, vitamin $\mathrm{C}$ and calcium (forty points), moderation of total fat, saturated fat, cholesterol, sodium and empty energy foods (thirty points), and balance of macronutrient and fatty acid ratios (ten points). We used recommended intake levels for Central America ${ }^{(27)}$ to calculate the adequacy of iron, calcium and vitamin $\mathrm{C}$.

\section{Anthropometry, lifestyle and socio-demographic variables}

We measured height, weight and waist circumference values in duplicate and computed the average. We categorized BMI as overweight $\left(\mathrm{BMI} \geq 25 \mathrm{~kg} / \mathrm{m}^{2}\right)$ and obese $\left(\mathrm{BMI} \geq 30 \mathrm{~kg} / \mathrm{m}^{2}\right)^{(28)}$. We calculated $24 \mathrm{~h}$ physical activity levels, expressed as metabolic equivalents/d, which we estimated using an interviewer-administered physical activity questionnaire that ascertained time spent in activities over the preceding year including sleeping, transportation, occupation, chores and leisure time ${ }^{(29)}$. We categorized current smoking status as yes or no. We defined participants as rural or urban based on a questionnaire regarding the amenities, location and neighbourhood of their residence. We calculated total annual expenditures, an indicator of economic wellbeing, by asking participants about food, non-food and housing expenditures, and durable goods ${ }^{(30)}$. This variable is expressed as per capita adult equivalent in order to account for different household compositions, and was converted to the US dollar in March 2004. Poverty rate was estimated using the poverty line, which is the cost of a basic 'food basket' to meet minimum daily energy requirements, plus an allowance for some non-food items ${ }^{(30)}$. We used a brief questionnaire to assess years of schooling obtained.

\section{Metabolic syndrome and its components}

We obtained finger prick blood samples after an overnight fast and analysed these samples with an enzymatic peroxidase dry chemistry method (Cholestech LDX System, Hayward, CA, USA) to determine HDL-cholesterol, TAG and glucose concentrations. Three blood pressure measurements were taken at least $3 \mathrm{~min}$ apart, after sitting quietly for at least $5 \mathrm{~min}$. Measurements were taken with a digital sphygmomanometer (A\&D model UA-767; A\&D Medical, Milpitas, CA, USA) on the left arm resting on a table at heart level. Three cuff sizes were available and selected for use based on arm circumference. If blood pressure measurements differed by more than $10 \mathrm{mmHg}$, a fourth was taken; otherwise the second and third measures were recorded. We used the American Heart Association/National Heart, Lung, and Blood Institute criteria for the metabolic syndrome ${ }^{(31)}$. This included having three or more of the following five risk factors: waist circumference $>102 \mathrm{~cm}$ (men) and $>88 \mathrm{~cm}$ (women), HDL-cholesterol $<400 \mathrm{mg} / 1$ $(1.0 \mathrm{mmol} / \mathrm{l})(\mathrm{men})$ and $<500 \mathrm{mg} / \mathrm{l}(1.3 \mathrm{mmol} / \mathrm{l})$ (women), TAG $\geq 500 \mathrm{mg} / \mathrm{l} \quad(1.7 \mathrm{mmol} / \mathrm{l}), \quad$ glucose $\geq 1000 \mathrm{mg} / \mathrm{l}$ ( $5.6 \mathrm{mmol} / \mathrm{l})$, or systolic blood pressure $\geq 130 \mathrm{mmHg}$ and/or diastolic blood pressure $\geq 85 \mathrm{mmHg}$. 


\section{Statistical analysis}

We obtained dietary data from 2157 adults; of these, we had fasting blood samples, blood pressure and anthropometric measures from 1326. We excluded participants with diabetes ( $n$ 24), self-reported energy intake $>23.0 \mathrm{MJ} / \mathrm{d}(5500 \mathrm{kcal} / \mathrm{d})$ ( $n$ 34), and women who were currently pregnant ( $n$ 17). Due to the low prevalence of smoking among women, we categorized those missing smoking status $(n$ 7) as non-smokers. The analysis includes 1220 adults (845 original trial participants and 375 spouses) on whom we had complete data for all covariates. Participants with dietary data but excluded from the analysis for missing outcomes or covariates were more likely to be male $(54 \%$ v. $39 \%, P<0.01)$, living in rural areas $(76 \% v .68 \%, P<0.01)$ and be more active $(1.55$ (SD 0.2) v. 1.51 (SD 0.2) metabolic equivalents/d, $P<0.01$ ) than were those who had complete data; there were no differences in any of the food scores. All of the dietary scores were normally distributed; we log-transformed total annual expenditures and TAG to meet normality assumptions. Due to the presence of spousal pairs in our sample and previous research suggesting sex differences in associations among diet scores and morbidity or mortality ${ }^{(32,33)}$, we stratified our analyses by sex. We used Pearson's correlations to estimate associations among the four scores and total energy intake. We used multiple linear regression models to assess the associations of each score with lifestyle and socio-demographic variables, and with the metabolic syndrome and its components $^{(31)}$. As the RFS and NRFS were intended to be used together, models for each of these two scores included the other. To facilitate comparison among the scores we present standardized regression coefficients and $95 \% \mathrm{CI}$. We calculated sources of energy in the population by summing the energy contribution from macronutrients, or the energy contribution from a specific food group, and divided these

Table 1. Characteristics of men and women surveyed in Guatemala, 2002-4

(Mean values and standard deviations)

\begin{tabular}{|c|c|c|c|c|}
\hline & \multicolumn{2}{|c|}{ Men ( $n$ 469) } & \multicolumn{2}{|c|}{ Women ( $n$ 751) } \\
\hline & Mean & SD & Mean & SD \\
\hline Age (years) & $34 \cdot 0$ & $6 \cdot 4$ & $31 \cdot 8$ & $5 \cdot 2$ \\
\hline Rural (\%) & \multicolumn{2}{|c|}{$65 \cdot 3$} & \multicolumn{2}{|c|}{$70 \cdot 5$} \\
\hline Current smoker (\%) & \multicolumn{2}{|c|}{$37 \cdot 6$} & \multicolumn{2}{|c|}{1.5} \\
\hline Schooling (years) & $5 \cdot 9$ & 3.4 & $5 \cdot 1$ & $3 \cdot 2$ \\
\hline Total annual expenditures (US\$)* & $1145 \cdot 3$ & 953.9 & $1106 \cdot 9$ & $929 \cdot 8$ \\
\hline Poverty rate (\%) & \multicolumn{2}{|c|}{$35 \cdot 3$} & \multicolumn{2}{|c|}{$36 \cdot 4$} \\
\hline Physical activity level (MET/d) & 1.7 & 0.3 & 1.4 & 0.1 \\
\hline BMl $\left(\mathrm{kg} / \mathrm{m}^{2}\right)$ & $25 \cdot 1$ & 3.7 & $26 \cdot 6$ & 4.8 \\
\hline$\geq 25 \mathrm{~kg} / \mathrm{m}^{2}(\%)$ & \multicolumn{2}{|c|}{$46 \cdot 2$} & \multicolumn{2}{|c|}{60.4} \\
\hline$\geq 30 \mathrm{~kg} / \mathrm{m}^{2}(\%)$ & \multicolumn{2}{|c|}{$10 \cdot 6$} & \multicolumn{2}{|c|}{$22 \cdot 9$} \\
\hline \multicolumn{5}{|l|}{ Dietary intakes } \\
\hline \multicolumn{5}{|l|}{ Total energy } \\
\hline $\mathrm{kJ} / \mathrm{d}$ & 14405.5 & 3722.5 & $11189 \cdot 7$ & 3515.4 \\
\hline $\mathrm{kcal} / \mathrm{d}$ & 3443.0 & 889.7 & 2674.4 & $840 \cdot 2$ \\
\hline Carbohydrate (\% energy) & $66 \cdot 0$ & $6 \cdot 9$ & 65.5 & $7 \cdot 1$ \\
\hline Protein (\% energy) & 11.5 & 1.4 & $11 \cdot 6$ & 1.5 \\
\hline Fat (\% energy) & 22.5 & $6 \cdot 9$ & $22 \cdot 8$ & $7 \cdot 2$ \\
\hline Saturated fat (\% energy) & $9 \cdot 0$ & $4 \cdot 2$ & $9 \cdot 2$ & $4 \cdot 3$ \\
\hline Monounsaturated fat (\% energy) & $7 \cdot 7$ & $2 \cdot 0$ & 7.7 & $2 \cdot 1$ \\
\hline Polyunsaturated fat (\% energy) & 4.3 & 0.8 & 4.2 & 0.9 \\
\hline Cholesterol (mg/d) & 491.9 & $256 \cdot 8$ & $369 \cdot 7$ & 207.5 \\
\hline Fibre (g/d) & $53 \cdot 2$ & $18 \cdot 0$ & $40 \cdot 4$ & $15 \cdot 5$ \\
\hline Sodium (mg/d) & $1413 \cdot 8$ & $566 \cdot 7$ & $1129 \cdot 4$ & $528 \cdot 0$ \\
\hline Iron (mg/d) & $20 \cdot 4$ & $7 \cdot 6$ & $16 \cdot 8$ & $7 \cdot 4$ \\
\hline Vitamin C (mg/d) & $440 \cdot 8$ & $318 \cdot 2$ & 354.9 & $243 \cdot 3$ \\
\hline Calcium (mg/d) & $1396 \cdot 2$ & $424 \cdot 0$ & $1082 \cdot 5$ & $378 \cdot 8$ \\
\hline Zinc (mg/d) & $23 \cdot 6$ & $6 \cdot 7$ & $17 \cdot 8$ & $6 \cdot 1$ \\
\hline \multicolumn{5}{|l|}{ Cardio-metabolic risk factors } \\
\hline Metabolic syndrome (\%) & \multicolumn{2}{|c|}{$22 \cdot 7$} & \multicolumn{2}{|c|}{$41 \cdot 1$} \\
\hline Waist circumference (cm) & \multirow{2}{*}{\multicolumn{2}{|c|}{$\begin{array}{ll}88.2 & \\
& 8.6\end{array}$}} & $91 \cdot 7$ & $11 \cdot 7$ \\
\hline$>102 \mathrm{~cm}$ men, $>88 \mathrm{~cm}$ women (\%) & & & \multicolumn{2}{|c|}{$60 \cdot 4$} \\
\hline Systolic blood pressure (mmHg) & $117 \cdot 0$ & $11 \cdot 7$ & $108 \cdot 0$ & $13 \cdot 1$ \\
\hline Diastolic blood pressure (mmHg) & 72.5 & $9 \cdot 6$ & $70 \cdot 0$ & $9 \cdot 6$ \\
\hline$\geq 130$ systolic/85 diastolic (mmHg) (\%) & \multicolumn{2}{|c|}{$17 \cdot 8$} & \multicolumn{2}{|c|}{7.9} \\
\hline Glucose (mg/l) & \multirow{2}{*}{\multicolumn{2}{|c|}{$\begin{array}{ll}918 & \\
& 18 \cdot 0\end{array}$}} & 904 & 99 \\
\hline$\geq 1000 \mathrm{mg} / \mathrm{l}(\%)$ & & & \multicolumn{2}{|c|}{$\begin{array}{ll}904 & \\
& 17 \cdot 3\end{array}$} \\
\hline TAG $\left(\mathrm{mg} / \mathrm{l}^{*}\right.$ & 1774 & 933 & 1614 & 819 \\
\hline$\geq 1500$ mg/l (\%) & \multicolumn{2}{|c|}{53.4} & \multicolumn{2}{|c|}{$48 \cdot 1$} \\
\hline HDL-cholesterol (mg/l) & \multirow{2}{*}{\multicolumn{2}{|c|}{$\begin{array}{ll}342 & \\
& 74.0\end{array}$}} & 393 & 107 \\
\hline$<400 \mathrm{mg} / \mathrm{l} \mathrm{men},<500 \mathrm{mg} / \mathrm{l}$ women $(\%)$ & & & & \\
\hline
\end{tabular}

MET, metabolic equivalents.

${ }^{*}$ Distributions are non-normal so values are medians and interquartile ranges. 
Table 2. Percentage of total energy intake contributed by food and beverage groups, Guatemala 2002-4*

\begin{tabular}{|c|c|c|}
\hline & Men ( $n$ 469) & Women ( $n$ 751) \\
\hline Tortillas & 33.3 & $30 \cdot 6$ \\
\hline Fruits/vegetables & $13 \cdot 0$ & $14 \cdot 1$ \\
\hline Sweets & $9 \cdot 7$ & $10 \cdot 3$ \\
\hline Powdered drinks/soda & $7 \cdot 6$ & $7 \cdot 1$ \\
\hline Bread/cereals & 4.6 & $6 \cdot 2$ \\
\hline Butter/cream & $6 \cdot 0$ & $6 \cdot 1$ \\
\hline Rice/noodles & 4.9 & $5 \cdot 2$ \\
\hline Beans & 4.7 & 4.6 \\
\hline Milk/cheese & $2 \cdot 3$ & $3 \cdot 1$ \\
\hline Chicken & $2 \cdot 7$ & 2.9 \\
\hline Meat & $2 \cdot 7$ & 2.9 \\
\hline Tacos/tamales & $2 \cdot 0$ & 2.5 \\
\hline Miscellaneous $†$ & $2 \cdot 2$ & $2 \cdot 0$ \\
\hline 'Western' foodsł & $2 \cdot 6$ & 1.5 \\
\hline Fish & $1 \cdot 1$ & 0.7 \\
\hline Alcohol & 0.9 & 0.01 \\
\hline
\end{tabular}

${ }^{*}$ For details of subjects and procedures, see Methods.

† Includes eggs, mayonnaise and broth.

$\ddagger$ Includes hamburgers, hot dogs, pizza and chips.

by total energy consumption. We inferred differences at $P<0 \cdot 05$. All statistical analyses were conducted using SAS software version 9.1 (SAS Institute, Cary, NC, USA).

\section{Results}

Our sample included 469 men and 751 women who had a mean age of 32.7 (SD 5.8) years (Table 1). The majority lived in rural areas; $36 \%$ were below the poverty line. Approximately onethird of men and almost no women were current smokers. The prevalence of overweight was $46 \%$ among men and $60 \%$ among women. Half of the population had elevated TAG and more than three-quarters had low HDL-cholesterol.

Carbohydrates contributed $66 \%$ of total energy; fat contributed $23 \%$, with saturated fat the primary contributor. Patterns of consumption were largely similar among men and women (Table 2). Tortillas provided one-third of total energy, followed by fruits and vegetables, sweets, and artificial powdered drinks/sodas. 'Western' foods, including hamburgers, hot dogs, pizza and chips, made up only $2 \%$ of energy intake. Alcohol consumption was very low, particularly among women, and accounted for $<1 \%$ of total energy intake.
Ranges of all four scores suggest wide variation in food intake (Table 3). Correlations of the scores with total energy and with one another were similar for men and women (Table 4). The NRFS was strongly correlated with both the FVS and RFS, but not with the DQI-I. All of the scores were correlated with total energy intake ( $r$ 0.23-0.49, $P<0.01)$. The DQI-I was positively associated with BMI (Table 5). Living in a rural environment was associated with higher NRFS and DQI-I scores among men and women, and with lower RFS among women. Years of schooling and total annual expenditures, both proxies of socio-economic status, were positively associated with the FVS and RFS, but were not significantly associated with the NRFS or DQI-I. Additional adjustment for energy intake did not alter these associations (data not shown).

The DQI-I was positively associated with waist circumference among both men and women, while the RFS was positively associated with TAG and glucose among men (Table 6). Additional adjustment for energy intake did not alter these associations (data not shown). To assess if these associations were mediated by adiposity we added BMI to the model; the associations between DQI-I and waist circumference $(\beta=0.004 ; 95 \%$ CI $-0.001,0.01)$ and between RFS and TAG $(\beta=0.08 ; 95 \%$ CI $-0.01,0.17)$ were attenuated. The association between the RFS and glucose $(\beta=0.12$; $95 \%$ CI $0 \cdot 02,0 \cdot 21$ ) was unaffected by this adjustment.

\section{Discussion}

There has been renewed emphasis on the study of dietary patterns versus individual nutrients in relation to health outcomes. This includes data-driven statistical methods ${ }^{(34)}$ and the development of dietary scores based on dietary guidelines or a priori knowledge of the health effects of diet ${ }^{(33,35)}$. Much of this research has been done in developed countries, with fewer studies examining how these scores perform in countries undergoing the nutrition transition.

As economic growth and globalization increase access to seasonal, processed and animal source foods, dietary variety and diversity may reflect consumption of both high- and low-quality foods. A study of ten countries found dietary diversity to be positively associated with energy availability at the household level in both rural and urban areas ${ }^{(36)}$, and

Table 3. Mean diet scores and components among men and women surveyed in Guatemala, 2002-4*

(Mean values, standard deviations and ranges)

\begin{tabular}{|c|c|c|c|c|c|c|c|}
\hline \multirow[b]{2}{*}{ Score } & \multirow[b]{2}{*}{ Theoretical range } & \multicolumn{3}{|c|}{ Men ( $n$ 469) } & \multicolumn{3}{|c|}{ Women ( $n$ 751) } \\
\hline & & Mean & SD & Reported range & Mean & SD & Reported range \\
\hline FVS & $0-39$ & 19.6 & 5.6 & $5-37$ & $18 \cdot 8$ & 5.5 & $3-34$ \\
\hline RFS & $0-16$ & 8.5 & $2 \cdot 8$ & $2-16$ & $8 \cdot 1$ & $2 \cdot 7$ & $2-16$ \\
\hline NRFS & $0-15$ & $6 \cdot 3$ & $2 \cdot 6$ & $1-15$ & $5 \cdot 7$ & $2 \cdot 3$ & $0-14$ \\
\hline DQI-I & $0-100$ & 69.1 & $6 \cdot 5$ & $48-87$ & 65.5 & $7 \cdot 6$ & $39-89$ \\
\hline Variety & $0-20$ & $16 \cdot 0$ & 3.8 & $3-20$ & $14 \cdot 8$ & 4.0 & $3-20$ \\
\hline Adequacy & $0-40$ & 32.4 & 3.3 & $19-40$ & 29.0 & 4.0 & $15-40$ \\
\hline Moderation & $0-30$ & $17 \cdot 8$ & $6 \cdot 0$ & $3-30$ & $18 \cdot 7$ & $5 \cdot 7$ & $3-30$ \\
\hline Balance & $0-10$ & 3.6 & $2 \cdot 2$ & $0-10$ & 3.6 & $2 \cdot 3$ & $0-10$ \\
\hline
\end{tabular}

DQI-I, Diet Quality Index-International; FVS, Food Variety Score; NRFS, Not Recommended Food Score; RFS, Recommended Food Score.

${ }^{*}$ For details of subjects and procedures, see Methods. 
Table 4. Pearson's correlations among four dietary scores and energy intake for men and women surveyed in Guatemala, 2002-4†

\begin{tabular}{|c|c|c|c|c|c|c|c|c|}
\hline & \multicolumn{4}{|c|}{ Men } & \multicolumn{4}{|c|}{ Women } \\
\hline & Energy & FVS & RFS & NRFS & Energy & FVS & RFS & NRFS \\
\hline FVS & $0.44^{\star}$ & & & & $0.49^{\star}$ & & & \\
\hline RFS & $0.37^{\star}$ & $0.59^{*}$ & & & $0.35^{\star}$ & $0.60^{*}$ & & \\
\hline NRFS & $0.40^{*}$ & $0.74^{*}$ & $0.36^{*}$ & & $0.43^{*}$ & $0.74^{*}$ & $0.45^{*}$ & \\
\hline DQI-I & $0.23^{*}$ & $0.15^{*}$ & $0.29^{*}$ & 0.05 & $0.33^{*}$ & $0.25^{*}$ & $0.29^{*}$ & 0.02 \\
\hline
\end{tabular}

DQI-I, Diet Quality Index-International; FVS, Food Variety Score; NRFS, Not Recommended Food Score; RFS, Recommended Food Score.

${ }^{*} P<0.0001$.

†Correlations between FVS or DQI-I with the RFS or NRFS are also adjusted for either the RFS or NRFS; other correlations are unadjusted.

several studies have found dietary diversity to be positively associated with overweight and obesity at the individual level ${ }^{(12,37-39)}$. The RFS attempts to address this issue by assessing variety among foods that are recommended by dietary guidelines ${ }^{(24)}$. Additionally, the NRFS was developed to be used with the RFS in order to better capture diet as a whole, as well as to assess the independent effect of low-quality foods on health outcomes ${ }^{(25)}$. The DQI-I incorporates food and nutrient components of the diet related to both undernutrition and chronic disease; it was developed to facilitate comparisons of diet quality among countries at various stages of the nutrition transition ${ }^{(9)}$. In the present analyses all of these scores were poorly related to cardio-metabolic risk.

While not designed to be nationally representative, we believe our sample provides value in describing dietary patterns and associations with lifestyle, socio-demographic and cardio-metabolic risk factors of Guatemalan young adults. Like our cohort, much of the Guatemalan population still resides in rural areas, or has recently migrated to urban areas ${ }^{(40)}$. Height, weight and BMI in this population are similar to estimates from a national sample of non-indigenous Guatemalans of a similar age ${ }^{(17)}$. Overall, the diet of our cohort was dominated by traditional foods, including tortillas and beans. Despite being in the midst of a nutrition transition, little energy consumption was due to foods that may be described as 'Western' (e.g. hamburgers, hot dogs, pizza, chips). However, a large portion of energy consumption was from sweets and sugar-sweetened beverages. 'Sweets/candy' is a single item included in the NRFS; a person consuming one piece of candy a week and a person consuming candy several times a day would both have received one point, which may have contributed to the poor performance of the score. Mean scores of the DQI-I were slightly higher for our sample than those calculated from nationally representative samples of adults in China (60.5 (SD 0.1)) and the USA (59.1 (SD 0.1) $)^{(9)}$. This information is difficult to interpret. It suggests that overall diet quality may be slightly higher among our Guatemalan cohort; however this population is experiencing dramatic increases in obesity and cardio-metabolic risk ${ }^{(41)}$.

The different associations of each of the scores with demographic and dietary variables indicate that these scores are capturing different aspects of the Guatemalan diet (and perhaps lifestyle), but the correlations among the different scores also indicate substantial overlap. This may reflect that populations in transition consume a mix of traditional and 'Western' dietary patterns, and consume foods considered nutritious in addition to refined, processed convenience foods. It is also possible that our dietary assessment instrument and/or its database were unable to capture the detail required for effectively utilizing these

Table 5. Associations of socio-demographic and lifestyle variables with dietary scores among adults surveyed in Guatemala, 2002-4*

\begin{tabular}{|c|c|c|c|c|c|c|c|c|}
\hline & \multicolumn{2}{|r|}{ FVS } & \multicolumn{2}{|r|}{ RFS } & \multicolumn{2}{|c|}{ NRFS } & \multicolumn{2}{|r|}{ DQI-I } \\
\hline & $\beta \dagger$ & $95 \% \mathrm{Cl}$ & $\beta \dagger$ & $95 \% \mathrm{Cl}$ & $\beta \dagger$ & $95 \% \mathrm{Cl}$ & $\beta \dagger$ & $95 \% \mathrm{Cl}$ \\
\hline \multicolumn{9}{|l|}{ Men } \\
\hline Age (years) & -0.08 & $-0.16,0.01$ & 0.09 & $0.01,0.19$ & -0.17 & $-0.25,-0.09$ & -0.07 & $-0.15,0.01$ \\
\hline Rural & $0 \cdot 14$ & $-0.07,0.35$ & -0.08 & $-0.28,0.11$ & 0.23 & $0.02,0.43$ & 0.24 & $0.05,0.43$ \\
\hline Smoker & 0.14 & $-0.05,0.33$ & 0.005 & $-0.17,0.18$ & 0.12 & $-0.07,0.30$ & -0.03 & $-0.20,0.14$ \\
\hline Schooling (years) & $0 \cdot 10$ & $0.001,0.20$ & $0 \cdot 11$ & $0.02,0.20$ & 0.01 & $-0.09,0.10$ & 0.01 & $-0.08,0.10$ \\
\hline Total annual expenditure (US\$) $\ddagger$ & 0.11 & $0.001,0.23$ & 0.21 & $0.10,0.31$ & -0.03 & $-0.15,0.08$ & -0.04 & $-0.14,0.07$ \\
\hline Physical activity level (MET/d) & 0.01 & $-0.07,0.08$ & -0.07 & $-0.14,0.01$ & 0.08 & $0.01,0.16$ & 0.03 & $-0.04,0.10$ \\
\hline BMl $\left(\mathrm{kg} / \mathrm{m}^{2}\right)$ & 0.04 & $-0.07,0.16$ & 0.01 & $-0.09,0.11$ & 0.03 & $-0.08,0.14$ & 0.10 & $0.003,0.21$ \\
\hline \multicolumn{9}{|l|}{ Women } \\
\hline Age (years) & 0.04 & $-0.04,0.12$ & 0.10 & $0.04,0.18$ & -0.11 & $-0.18,0.04$ & -0.09 & $-0.17,-0.01$ \\
\hline Rural & $0 \cdot 12$ & $-0.05,0.28$ & $-0 \cdot 18$ & $-0.32,-0.08$ & 0.30 & $0.15,0.44$ & 0.31 & $0.14,0.49$ \\
\hline Schooling (years) & 0.04 & $-0.04,0.12$ & 0.13 & $0.06,0.20$ & -0.07 & $-0.14,0.1$ & 0.02 & $-0.07,0.10$ \\
\hline Total annual expenditures (US\$)‡ & 0.26 & $0.18,0.34$ & 0.23 & $0.16,0.30$ & 0.05 & $-0.03,0.12$ & 0.07 & $-0.01,0.16$ \\
\hline Physical activity level (MET/d) & 0.03 & $-0.14,0.20$ & 0.05 & $-0.09,0.19$ & 0.004 & $-0.14,0.15$ & -0.06 & $-0.24,0.11$ \\
\hline BMl $\left(\mathrm{kg} / \mathrm{m}^{2}\right)$ & -0.03 & $-0.10,0.04$ & -0.02 & $-0.07,0.04$ & 0.004 & $-0.05,0.06$ & 0.07 & $0.01,0.14$ \\
\hline
\end{tabular}

DQI-I, Diet Quality Index-International; FVS, Food Variety Score; MET, metabolic equivalents; NRFS, Not Recommended Food Score; RFS, Recommended Food Score. * Models are adjusted for all other variables listed in the table; RFS also adjusted for NRFS and vice versa.

† Standardized regression coefficients.

$\ddagger$ Log transformed. 
diet quality scores. For example, we were not able to distinguish between high- and low-fat dairy products, or between whole and refined grains, both of which are important aspects of diet quality. Additionally, FAO food balance sheets from the last several decades indicate an increased contribution of fats, animal products and refined sugar, and decreased contribution of cereals, legumes and fruits/vegetables to total energy availability ${ }^{(42)}$. Our instrument cannot capture changes in cooking habits, such as amount and types of oils used, that are likely occurring consequent to these changes in the food supply. Another limitation of our analysis is the cross-sectional nature of our data. The rapidly changing food supply will not be captured when using a dietary intake instrument administered at one point in time, and may contribute to unmeasured confounding in studies involving populations undergoing the nutrition transition.

In developing countries it is important to assess diet quality in terms of both micronutrient adequacy as well as the prevention of overweight and chronic conditions. Diet quality is very difficult to assess; diet scores aim to do just that, but there is a great deal of subjectivity in their composition. They vary in foods or nutrients included, the cut-offs used, and the weight given to subcomponents of the score. A recent review of a wide range of dietary scores concluded that existing indices of diet quality often do not predict morbidity or mortality better than individual dietary factors ${ }^{(43)}$. Diet scores can be used to assess adherence to dietary guidelines or consumption of specific foods, but may not be capable of assessing overall diet quality until more is known about patterns of consumption in transitioning populations. It is likely that good measures of diet quality will be more complex to design and interpret in populations experiencing both under- and over-nutrition. More research is needed to clarify these associations, and better measures of diet quality need to be designed and evaluated specifically for these populations. Until then it may be more appropriate to focus on specific aspects of the diet that are important indicators of diet quality in this population, such as fruit and vegetable intake, reduction in the consumption of sweetened beverages, replacement of carbohydrates with unsaturated fats, and overall moderation in energy intake.

\section{Acknowledgements}

We gratefully acknowledge financial support from the National Institutes of Health (R01 TW005598: PI Martorell; R01 HD046125: A. D. S.) and a pre-doctoral fellowship to C. O. G. from the American Heart Association. This study would not have been possible without the work and dedication of the INCAP field team, past and present investigators and collaborators, and of course continued participation of the INCAP cohort. No author has any conflict of interest. C. O. G. performed all statistical analyses and drafted the manuscript. All authors participated in the study design, provided critical revision of the paper, and read and approved the final manuscript.

\section{References}

1. Mendez MA, Monteiro CA \& Popkin BM (2005) Overweight exceeds underweight among women in most developing countries. Am J Clin Nutr 81, 714-721.

2. Reddy KS \& Yusuf S (1998) Emerging epidemic of cardiovascular disease in developing countries. Circulation 97, 596-601. 
3. King H, Aubert RE \& Herman WH (1998) Global burden of diabetes, 1995-2025: prevalence, numerical estimates, and projections. Diabetes Care 21, 1414-1431.

4. Drewnowski A \& Popkin BM (1997) The nutrition transition: new trends in the global diet. Nutr Rev 55, 31-43.

5. Eckhardt CL, Torheim LE, Monterrubio E, et al. (2007) The overlap of overweight and anaemia among women in three countries undergoing the nutrition transition. Eur J Clin Nutr 62, 238-246.

6. Eckhardt CL (2006), Micronutrient Malnutrition, Obesity, and Chronic Disease in Countries Undergoing the Nutrition Transition: Potential Links and Program/Policy Implications, IFPRI Report No. FCND, Discussion Paper 213. Washington, DC: International Food Policy Research Institute.

7. Singh RB, Niaz MA, Rastogi SS, et al. (1998) Current zinc intake and risk of diabetes and coronary artery disease and factors associated with insulin resistance in rural and urban populations of North India. J Am Coll Nutr 17, 564-570.

8. Kennedy E (2004) Dietary diversity, diet quality, and body weight regulation. Nutr Rev 62, S78-S81.

9. Kim S, Haines PS, Siega-Riz AM, et al. (2003) The Diet Quality Index-International (DQI-I) provides an effective tool for cross-national comparison of diet quality as illustrated by China and the United States. J Nutr 133, 3476-3484.

10. Popkin BM, Lu B \& Zhai F (2002) Understanding the nutrition transition: measuring rapid dietary changes in transitional countries. Public Health Nutr 5, 947-953.

11. Torheim LE, Ouattara F, Diarra MM, et al. (2004) Nutrient adequacy and dietary diversity in rural Mali: association and determinants. Eur J Clin Nutr 58, 594-604.

12. Savy M, Martin-Prevel Y, Danel P, et al. (2007) Are dietary diversity scores related to the socio-economic and anthropometric status of women living in an urban area in Burkina Faso? Public Health Nutr 10, 1-10.

13. Hatloy A, Torheim LE \& Oshaug A (1998) Food variety - a good indicator of nutritional adequacy of the diet? A case study from an urban area in Mali, West Africa. Eur J Clin Nutr 52, 891-898.

14. Savy M, Martin-Prevel Y, Sawadogo P, et al. (2005) Use of variety/diversity scores for diet quality measurement: relation with nutritional status of women in a rural area in Burkina Faso. Eur J Clin Nutr 59, 703-716.

15. World Health Organization (2007) Global Database on Child Growth and Malnutrition. http://www.who.int/nutgrowthdb/ reference/en/ (accessed 1 October 2007).

16. Pan American Health Organization (2007) Basic Country Health Profiles for the Americas: Guatemala. http://www. paho.org/english/sha/profiles.htm (accessed 1 October 2007).

17. Guatemalan Ministry of Health and the Centers for Disease Control and Prevention (2002) Encuesta Nacional de Salud Materno-Infantil (National Maternal and Child Health Survey). Guatemala City: Guatemalan Ministry of Health and the Centers for Disease Control and Prevention.

18. World Health Organization (2007) Global Database on Body Mass Index. http://www.who.int/bmi/index.jsp (accessed 1 October 2007).

19. Pan American Health Organization (2007) Central American Diabetes Initiative (CAMDI): Survey of Diabetes, Hypertension, and Chronic Disease Risk Factors. Villa Nueva, Guatemala 2006. Washington, DC: Pan American Health Organization.

20. Martorell R, Habicht JP \& Rivera JA (1995) History and design of the INCAP longitudinal study (1969-77) and its follow-up (1988-89). J Nutr 125, 1027S-1041S.

21. Stein AD, Melgar P, Hoddinott J, et al. (2008) Cohort profile: the Institute of Nutrition of Central America and Panama (INCAP) Nutrition Trial Cohort Study. Int J Epidemiol 3, 716-720.

22. Grajeda R, Behrman JR, Flores R, et al. (2005) The human capital study 2002-04: tracking, data collection, coverage, and attrition. Food Nutr Bull 26, S15-S24.
23. Rodriguez MM, Mendez H, Torun B, et al. (2002) Validation of a semi-quantitative food-frequency questionnaire for use among adults in Guatemala. Public Health Nutr 5, 691-699.

24. Kant AK, Schatzkin A, Graubard BI, et al. (2000) A prospective study of diet quality and mortality in women. JAMA $\mathbf{2 8 3}$, 2109-2115.

25. Michels KB \& Wolk A (2002) A prospective study of variety of healthy foods and mortality in women. Int J Epidemiol 31, 847-854.

26. Drewnowski A, Henderson SA, Driscoll A, et al. (1997) The dietary variety score: assessing diet quality in healthy young and older adults. $J$ Am Diet Assoc 97, 266-271.

27. Torun B, Menchu M \& Elias L (1994) Recomendaciones Dieticas Diarias de INCAP (Recommended Daily Intakes from INCAP). Guatemala City: Institute of Nutrition of Central America and Panama.

28. World Health Organization (1995) Physical Status: The Use and Interpretation of Anthropometry. Geneva: WHO.

29. Gregory CO, Ramirez-Zea M, Martorell R, et al. (2007) Activities contributing to energy expenditure among Guatemalan adults. Int J Behav Nutr Phys Act 4, Paper no. 48. http://www.ijbnpa.org/content/4/1/48.

30. Maluccio JA, Martorell R \& Ramirez LF (2005) Household expenditures and wealth among young Guatemalan adults. Food Nutr Bull 26, S110-S119.

31. Grundy SM, Cleeman JI, Daniels SR, et al. (2005) Diagnosis and management of the metabolic syndrome: an American Heart Association/National Heart, Lung, and Blood Institute Scientific Statement. Circulation 112, 2735-2752.

32. Fogli-Cawley JJ, Dwyer JT, Saltzman E, et al. (2007) The 2005 Dietary Guidelines for Americans and insulin resistance in the Framingham Offspring Cohort. Diabetes Care 30, 817-822.

33. McCullough ML, Feskanich D, Stampfer MJ, et al. (2002) Diet quality and major chronic disease risk in men and women: moving toward improved dietary guidance. Am J Clin Nutr 76, 1261-1271.

34. Newby PK \& Tucker KL (2004) Empirically derived eating patterns using factor or cluster analysis: a review. Nutr Rev 62, 177-203.

35. Kant AK (1996) Indexes of overall diet quality: a review. J Am Diet Assoc 96, 785-791.

36. Hoddinott J \& Yohannes Y (2002) Dietary Diversity as a Food Security Indicator, IFPRI Report No. FCND Briefs 136. Washington, DC: International Food Policy Research Institute.

37. McCrory MA, Fuss PJ, McCallum JE, et al. (1999) Dietary variety within food groups: association with energy intake and body fatness in men and women. Am J Clin Nutr 69, $440-447$.

38. Azadbakht L, Mirmiran P, Esmaillzadeh A, et al. (2006) Dietary diversity score and cardiovascular risk factors in Tehranian adults. Public Health Nutr 9, 728-736.

39. Ponce X, Ramirez E \& Delisle H (2006) A more diversified diet among Mexican men may also be more atherogenic. J Nutr 136, 2921-2927.

40. Torun B (2000) Physical activity patterns in Central America. In Obesity and Poverty, pp. 29-40 [M Pena and J Bacallao, editors]. Washington, DC: Pan American Health Organization.

41. Gregory CO, Martorell R, Venkat Narayan K, et al. (2008) Five-year changes in adiposity and cardio-metabolic risk factors among Guatemalar young adults. Public Health Nutr (Epulication ahead of print version 15 August 2008).

42. Bermudez OI \& Tucker KL (2003) Trends in dietary patterns of Latin American populations. Cad Saude Publica 19, Suppl. 1, S87-S99.

43. Waijers PM, Feskens EJ \& Ocke MC (2007) A critical review of predefined diet quality scores. Br J Nutr 97, 219-231. 